\title{
LA FILOSOFÍA CONFIGURADORA DEL SER DEL PERONISMO
}

\author{
The Philosophy that Shapes the Being of Peronism
}

\section{Carlos Daniel Lasa}

\author{
Universidad Nacional de Villa María, \\ Universidad Católica de Córdoba, Universidad Católica de Salta \\ cdlasa@yahoo.com.ar
}

\section{Resumen:}

La tesis central del presente trabajo consiste en afirmar que el peronismo es la traducción del fascismo italiano en la política argentina, entendiendo que la esencia del fascismo está inspirada en la filosofía actualista del pensador italiano Giovanni Gentile. Asimismo, este actualismo es el producto de la disociación operada por el mismo filósofo, hacia fines del siglo XIX, entre materialismo y dialéctica. La metodología de estudio empleada es la transpolítica por cuanto se propone examinar al fenómeno del peronismo desde una rigurosa problemática filosófica con el fin de aprehender su esencia propia. El texto principal elegido para el referido examen, sin excluir otros, es la Conferencia que Perón diera en el Congreso Nacional de Filosofía, celebrado en Mendoza (República Argentina) en 1949, y que más adelante va a publicarse bajo el título de La Comunidad organizada.

\section{Palabras clave:}

Fascismo, Peronismo, Giovanni Gentile, Juan Domingo Perón, Análisis transpolítico, Augusto Del Noce.

\begin{abstract}
:
This paper argues that Peronism is an adaptation of the Italian Fascism into Argentine politics, understanding that the essence of Fascism is inspired by the philosophy of Giovanni Gentile. Likewise, the Actualism is the product of the dissociation operated by the same philosopher - towards the end of the 19th Century-, between materialism and dialectics. With the aim of analyze the Peronist Movement from a rigorous philosophical point of view, it is used the transpolitics interpretation proposed by Del Noce. The main text chosen for the aforementioned examination, without excluding others, is the conference that Perón gave at the National Congress of Philosophy, held in Mendoza (Argentina) in 1949, and which was later published as The Organized Community.
\end{abstract}




\section{Keywords:}

Fascism, Peronism, Giovanni Gentile, Juan Domingo Perón, Augusto Del Noce.

Recibido: 23/02/2021

Aceptado: 25/06/2021

\section{INTRODUCCIÓN: PROPÓSITO Y METODOLOGÍA}

El peronismo es un fenómeno político omni-abarcador de la vida política argentina desde hace ya más de setenta años. Esta omnipresencia, a nuestro juicio, no sólo ha condicionado la vida política nacional, sino que ha determinado el ethos cultural del argentino medio. Sin embargo, esta importancia no ha sido correlativa a los estudios que se ocupan de precisar su naturaleza propia: huelgan este tipo de trabajos. Y sin ellos, la real dimensión de la praxis política y cultural generada en Argentina desde mediados de la década del cuarenta no puede explicarse en profundidad.

Desde esta perspectiva, consideramos que los hechos históricos, pese a su esencial diversidad, resultan inteligibles en virtud de una secuencia que los enhebra y les otorga sentido. Y esa secuencia no pertenece al orden fáctico, sino que dimana del espíritu humano, del pensamiento.

Este supuesto nos ha conducido a adoptar, para el estudio del fenómeno del peronismo, el método transpolítico, aquel que precisara Renzo De Felice en virtud de su estudio sobre las interpretaciones vertidas acerca del fascismo italiano. En efecto, ha sido este autor quien ha acuñado este término, en su importante escrito Le interpretazioni del fascismo (De Felice, 1976: 100-112), para calificar las lecturas que sobre este fenómeno hicieran Ernst Nolte y Augusto Del Noce. Con esta denominación, De Felice caracterizaba a aquellas interpretaciones del fascismo que, sin negar el análisis histórico, pretendían examinarlo, fundamentalmente, a partir de una rigurosa problemática filosófica con el fin de aprehender su mismísima esencia y su significado más profundo (De Felice, 1976: 102-103), dejando de lado consideraciones secundarias del mismo.

De allí, entonces, que la pregunta por la esencia del peronismo sea, a nuestro juicio, la pregunta que permite alumbrar una respuesta desde la cual todas las manifestaciones históricas del mismo resultarán inteligibles. Para alcanzar este propósito nos será menester llevar un trabajo de análisis y de síntesis de los escritos del fundador del movimiento peronista: Juan Domingo Perón. 


\section{INTERPRETACIONES DEL PERONISMO}

En su importante estudio sobre el peronismo (Del Barco, 1983), el Profesor Ricardo del Barco, fundándose en Alberto Ciria, refiere la existencia de siete interpretaciones del peronismo: 1. El peronismo visto como una variante local del nazi-fascismo (refiere, dentro de esta interpretación, el escrito de Fayt titulado La Naturaleza del Peronismo (Fayt, 2007); 2. el peronismo considerado como una forma de totalitarismo (aquí alude a la posición de Gino Germani (1968) aunque con una particularidad propia: la participación real del pueblo en la cosa pública; 3. el peronismo considerado como bonapartismo y bismarckismo; 4. el peronismo identificado con el populismo; 5. el peronismo visto desde sus fuentes (es la posición de Alberto Ciria); 6. el peronismo en su vertiente socialista (posición sostenida por John W. Cooke); 7. el peronismo interpretado desde sí mismo (se señala, dentro de esta posición, la obra de Raúl Mende titulada El Justicialismo). Consideramos importante señalar que tanto el escrito de Ciria como el de Mende destacan, dentro del peronismo, la presencia de la doctrina católica.

Ahora bien: tanto la segunda como la cuarta de las interpretaciones son demasiado genéricas lo cual impide precisar la esencia propia del movimiento peronista. En este sentido, consideramos que tanto la postura de Fayt como la de aquellos que entienden al peronismo como bonapartismo y socialismo sí se esfuerzan por captar la esencia del peronismo, aunque no coincidan en la interpretación de la misma.

Nos interesa detenernos en el análisis de la obra de Fayt por cuanto la tesis de la misma, en su formulación, coincide con la nuestra. Para Carlos Fayt, la esencia del peronismo coincide con el fascismo italiano, y este último vinculado con diversas formas de nacionalismo (Fayt, 2007: 5).

La analogía entre el peronismo y el fascismo, sostiene Fayt, se funda en la presencia de ciertos caracteres comunes, cuales son: a. La precedencia de la acción respecto de la doctrina; b. la asunción de los valores orden, jerarquía y disciplina; c. la negación del liberalismo y del marxismo; d. la concepción de movimiento y de la Nación como un todo animado de una sola doctrina y con una sola voluntad: la del líder; e. la negación de la lucha de clases y la instauración del corporativismo; f. el desprecio por la democracia (Fayt, 2007: 6).

Desde nuestra óptica, también el peronismo es la traducción del fascismo en Argentina; sin embargo, mantenemos una profunda divergencia respecto de la tesis de Fayt en lo que respecta no sólo a la naturaleza del fascismo (y, por ende, del peronismo), sino también en relación a la estrecha vinculación que establece entre fascismo y nacionalismo.

El peronismo no es, a nuestro juicio, "(...) un producto del nacionalismo argentino $(\ldots)^{\prime \prime}$ (Fayt, 2007: 6); para nosotros existe una diferencia fundamental entre el nacionalismo argentino y el fascismo. El primero reconoce, sin ambages, la existencia previa de la Nación y de los derechos de la persona humana a la constitución del Estado. Emilio Juan Samyn Duco, en su escrito acerca del nacionalismo, afirma que, para el nacionalismo: "La nación pertenece al orden natural. Es naturaleza. Su origen está en la familia misma, que trasciende, inicialmente, al clan y a la tribu, por una acción cuantitativa, hasta devenir completamente en 'nación'” (Samyn Duco, 1978: 
11). Y aclara que por natural debe entenderse aquello que ha sido dado al hombre $y$ que, en consecuencia, no es un producto de su decisión. Uno de los destacados exponentes del nacionalismo argentino, Julio Meinvielle, sostenía que la fundamentación de la política no podía encontrarse ni en el fisicismo maurrasiano, el cual es amoral, ni en la estatolatría del fascismo, el cual es inmoral, ni tampoco en la voluntad general del liberalismo que disuelve el orden y conduce a la anarquía o al despotismo, sino en la naturaleza social del hombre. De allí que la realidad política pertenezca al orden moral por cuanto se encuentra fundada en un "movimiento intrínsecamente moral y moralmente obligatorio" ordenado al bien común. La política, afirma Meinvielle sin ambages, es un capítulo de la moral y responde a los postulados de la ley natural (Meinvielle, 1974: 38-39). La sociedad política, para Meinvielle, reconoce en la familia y en las asociaciones naturales su causa material y en el bien común su causa final. De allí el rechazo tanto del liberalismo como de cualquier clase de estatismo que subsume al hombre en el Todo.

Para Meinvielle, el hombre es, en su orden, un todo autónomo que en razón de su destino se ordena a Dios, y el Estado se deriva del mismo hombre y se ordena a la perfección de este último (Meinvielle, 1974: 45-51). Jordán Bruno Genta, otro conspicuo nacionalista argentino, siendo partidario de "... una férrea Dictadura nacional de base militar" (Genta: 96), no deja de establecerle, a esta última, dos límites bien precisos: el decálogo y el derecho natural (Genta: 96).

Desde nuestra postura, contrariamente a lo sostenido por Fayt, y tal como lo desarrollaremos más adelante, el fascismo no reconoce la existencia de ninguna realidad que sea previa a la voluntad única manifestada en el estado ético fascista. Este último es, precisamente, la causa eficiente configuradora de la Nación. Para Mussolini, el Estado antecede a la Nación; de allí el rechazo, por parte del fascismo, de la existencia de derechos de la persona humana anteriores al estado. El nacionalismo, que defiende derechos previos a la constitución del estado, era considerado por Mussolini como contra-revolucionario, como conservador. Mussolini, fiel a la concepción actualista, contrariamente al pensamiento nacionalista, daba prioridad absoluta a la acción en detrimento de la dimensión teórica que, para el nacionalismo, era anterior y también expresión de la dimensión ontológica de lo real. La voluntad, para Mussolini, desligada de un orden eterno de las cosas que la inteligencia humana buscaba develar, se establece en un centro de energía refractario a toda naturaleza, a todo orden dado. El centro de energía equivale a fuerza, y la política es su entera manifestación.

A la anterior discrepancia se añade esta otra: el peronismo, desde nuestra óptica, tiene una ideología bien determinada desde sus comienzos, y la misma precede a la acción política, o si se quiere, la misma es acción política. Mostraremos esto cuando nos ocupemos de analizar la doctrina de Perón. Fayt, por el contrario, sostiene que el peronismo no posee una ideología clara en sus comienzos (Fayt, 2007: 9).

No podemos dejar de hacer una breve referencia a aquella interpretación que considera al peronismo como bonapartismo, esto es, como un producto de una yuxtaposición de elementos tomados del liberalismo y del marxismo. Este término había sido empleado por Marx para designar una especie política caracterizada por el equilibrio, pero indefinida en su esencia ideológica, y que, por esta razón, deja 
conformes a todos los actores de la realidad política con el único fin de perpetuarse en el poder. Desde nuestra perspectiva, el peronismo tiene identidad propia y no es el fruto de una mixtura híbrida compuesta por un ingrediente liberal y otro marxista. Consideramos que el peronismo tiene un cuerpo doctrinal bien definido expresado en la conferencia que Perón ofreciera, en la ciudad de Mendoza, a propósito del Congreso Nacional de Filosofía del año 1949.

\section{NUESTRA LECTURA}

\subsection{El fascismo}

Precedentemente señalamos que, según nuestra posición, el peronismo no es otra cosa que la traducción de la doctrina fascista a la política argentina. Ahora bien, el fascismo es, a nuestro juicio, el producto de la reforma que operara dentro del marxismo el destacado filósofo italiano Giovanni Gentile, a fines del siglo XIX, alumbrando la filosofía denominada "actualista". Analicemos esta cuestión.

La historia contemporánea, nos dice Augusto Del Noce, no es sino el resultado de una no-filosofía o de una filosofía que se hace mundo: el marxismo. El marxismo anula el momento filosófico por cuanto no considera a la filosofía como interpretación de lo que acontece sino que la entiende como transformación (tesis XI sobre Feuerbach).

Este imperativo de la acción será llevado al extremo por Gentile, a punto tal que le quitará al marxismo su materialismo con el objetivo de que devenga una "filosofía" de la acción total, una filosofía para la cual sólo sea real la pura acción. La acción, para el actualismo, no será guiada por principios, por valores, sino que la única instancia, tanto en la esfera del individuo como en el de la política será la acción misma. La lógica del descubrimiento es reemplazada por la lógica de la construcción. En efecto, ya no interesa buscar la respuesta adecuada (verdad) a la pregunta formulada sino sólo interesa actuar en orden al posicionamiento del propio querer.

Dentro de ese actuar, las ideas ya no son expresión de lo que las cosas son sino que están vistas como simples instrumentos que permiten construir un mundo de significaciones como expresión plena del querer. Gentile proponía, en su escrito titulado La filosofia di Marx (Gentile, 2003), inverare ${ }^{1}$ a Marx. En el prefacio de 1899, Gentile expresa: "Reúno aquí dos estudios críticos sobre aquella, finalmente cuestionada, filosofía de Marx, en torno a la cual se viene discutiendo hoy con mucho ardor tanto por parte de sus seguidores como por parte de sus adversarios sin la esperanza de llegar a un posible acuerdo, no sólo en lo que respecta a las doctrinas especiales, sino en relación a la misma dirección general". Y a renglón seguido se pregunta: "¿Fue, él, verdaderamente un materialista, o no? ¿Y qué doctrina se comprende bajo aquel nombre afortunado de materialismo histórico echado a rodar por él mismo por el mundo entero, junto con su idea revolucionaria? ¿Existe,

\footnotetext{
${ }^{1}$ Vocablo italiano que puede traducirse como "conferir verdad" o, también, puede entenderse como "actuación, cumplimiento". Gentile, al pretender inverare a Marx, estaba llevando a la doctrina marxista a su plena verdad y absoluto cumplimiento.
} 
verdaderamente, una relación entre este materialismo histórico y el materialismo propiamente dicho, metafísico?" (Gentile, 2003: 5).

Gentile no tiene duda alguna en la respuesta adecuada a dichos interrogantes. Para él, hablar en términos de materialismo histórico equivale a plantear un oxímoron. Este materialismo ha conducido a Marx a sostener, de modo totalmente erróneo, que no es la conciencia del hombre la que establece su ser sino que es lo social lo que determina su conciencia (Gentile, 2003: 25). Precisamente aquí anida, para Gentile, la esencial contradicción. Refiere Gentile: “¿Qué clase de materialismo es éste? (se refiere al de Marx). Como todo materialismo no reconoce como real más que aquello que es sensible; pero esto sensible, que para todo otro materialismo es estático, para éste (el de Marx) es dinámico, está en perpetuo fieri; de allí su denominación de materialismo histórico. He aquí que este materialismo, para ser histórico, está obligado a negar, en su construcción especulativa, su propio fundamento: que fuera de lo sensible no existe ninguna otra realidad. Esto lo obliga a rechazar los caracteres esenciales de toda intuición materialista: como, por ejemplo, la concepción atomista de la sociedad, y al mismo naturalismo. Éste es, en suma, un materialismo que para ser histórico no es más materialismo. Una intrínseca, profunda e insanable contradicción lo afecta" (Gentile, 2003: 161).

Para Gentile, sólo el espíritu, en tanto movimiento inagotable, es la única instancia que tiene prioridad absoluta por sobre toda la realidad. La praxis, considerada como actividad creadora, encuentra su raíz en la actividad del yo, el cual se da forma a sí mismo, configurando al objeto. Para Gentile, sólo el pensamiento es dialéctico, sólo él es praxis, actividad creadora, por medio de la cual verum et factum convertuntur (Gentile, 2003: 87).

Ni dialéctica de la materia (Marx), ni dialéctica de la Idea (Hegel), sino dialéctica del pensar, actividad del conocer. Ésta es la verdadera filosofía de la praxis. Expresa Gentile: "Cuando se conoce, se construye, se hace el objeto, y cuando se hace o se construye un objeto, se lo conoce; por lo tanto el objeto es un producto del sujeto; $y$, puesto que no existe un sujeto sin objeto, es necesario agregar que el sujeto, a medida que va haciendo o construyendo el objeto, se va haciendo o construyendo a sí mismo" (Gentile, 2003: 77). Para no dejar lugar a dudas en el sentido de que el centro de lo real está constituido por el Yo absoluto, agrega: "El conocimiento, en suma, es un desarrollo continuo; y puesto que no es esencialmente más que una relación de dos términos correlativos, equivale a un progresivo desarrollo de estos dos términos. Mientras tanto, la raíz, la causa permanente de este desarrollo reside en la actividad, en el hacer del sujeto, que se forma a sí mismo, formando al objeto; crescit et concrescit; $\dot{\varepsilon} \pi \hat{\delta} \delta o \sigma \iota \varsigma \dot{\varepsilon} \phi^{\prime} \alpha \dot{u} \tau \hat{\omega}$ (Aristóteles)" (Gentile, 2003: 77).

Pero el sujeto al que hace referencia Gentile no es el yo empírico sino el Yo universal e infinito. ¿Qué significa esta afirmación? Para que exista un conocimiento, nos dice el pensador italiano, es preciso que el objeto se resuelva en el sujeto, que se haga el sujeto. Pero, ¿por qué podemos pensar a un objeto que, estando en nosotros mismos, lo concebimos como distinto? Porque existe un acto que percibe, de modo simultáneo, al objeto y al sujeto. Ese acto de apercepción es unicidad absoluta, principio primordial, infinitud. El hombre individual, frente a esta apercepción infinita es un objeto, una posición del Yo universal, un momento del mismo; el hombre, como 
realidad meramente individual, está destinado a ser superado por la universalidad del Yo (apercepción trascendental).

La apercepción trascendental, si bien no puede vivir sino de los momentos finitos (los objetos de conocimiento que va poniendo), no se identifica, sin embargo, con ninguno de ellos; antes bien, los va poniendo y los fagocita trascendiéndolos, y en esta acción inagotable de poner lo "otro" y devorarlo consiste la vida del Yo, del espíritu infinito: un devenir eterno. Fuera del acto de pensar, de este eterno devenir, nada existe. De allí el nombre de actualismo que se le otorga a la filosofía gentiliana.

La filosofía de Gentile representa la revolución en estado puro. Vittorio Mathieu ha llegado a afirmar que Gentile, más allá de la interpretación que haya hecho de su propia doctrina, es el verdadero filósofo de la contestación global, infinitamente más que Marcuse (Del Noce, 1992: 192). En este sentido, Gramsci es un gentialiano avant la lettre, operando, respecto del pensamiento de Gentile, una "re-traducción historizante" (Del Noce, 1992: 131). En lugar del Yo infinito, del dios-inmanente del cual hablaba Gentile, Gramsci procede a historizar el pensamiento mismo considerándolo en tanto concepción del mundo (Gramsci, 2001: "La filosofia di Benedetto Croce", $\S 44$, p. 1330). Toda afirmación filosófica es verdadera en un determinado tiempo histórico, y la misma no es sino la expresión necesaria e inescindible de una determinada acción histórica, de una determinada praxis (Gramsci, 2001: "La filosofia di Benedetto Croce", § 14, p. 1402).

La innovación que ha presentado Gramsci respecto de la doctrina marxista (esto es, la concepción de la sociedad civil como el complejo de relaciones ideológicoculturales de la vida espiritual y el abandono del economicismo y del materialismo marxista) no hubiese sido realizable sino a la luz de la filosofía gentiliana. La historia ya no es más, en primer lugar, historia económica, sino historia de las concepciones de mundo, historia de la filosofía. ¿No es acaso el resultado, esta posición, de la crítica marxista llevada a cabo por Gentile en su obra La filosofia di Marx? Pero, como se pregunta Del Noce, ¿no es pues el actualismo el producto de la disociación del marxismo respecto del materialismo y del economicismo? En realidad, como afirma Del Noce, "Gramsci, en su trabajo de 're-traducción historizante' no encuentra a Marx, sino, por el contrario, a Gentile" (Del Noce, 1992: 131).

Ahora bien, ya expresamos que el fascismo es el resultado de la operación llevada a cabo por Gentile, a través de La filosofia di Marx, de superación del marxismo bajo la forma de cumplimiento. La identidad entre pensamiento y acción, propia del actualismo, es la esencia del fascismo. Gentile tenía necesidad de ese fascismo nacido con Mussolini ya que era una filosofía ordenada, toda ella, a la acción; a su vez, a Mussolini le urgía una legitimación cultural, y la halló en el actualismo (Del Noce, 1992: 131).

Pero entonces, ¿qué queda luego de afirmar que el pensamiento es puro acto y, fuera del mismo, nada existe? La respuesta ya se encuentra en la misma pregunta ya que, ciertamente, no queda otra cosa más que la pura acción. Y si queda sólo la acción, la misma no saldrá jamás de sí misma: de una acción se sucederá la siguiente, y así sucesivamente. Esto es lo que se conoce como activismo, o sea, una acción que es querida por sí misma sin encontrarse subordinada a un orden de fines previos a sí. 
En este caso, ya no puede existir valor alguno que otorgue sentido a la acción; los valores serán considerados como tales si, en tanto meras herramientas, ayudan a promover la acción. Y si todo está ordenado en función de la acción, también lo será la persona humana. Esta última, como lo señala Del Noce, pasará a tener una condición de instrumento o de obstáculo a superar (Del Noce, 1992: 353).

Como veremos más adelante, esta filosofía actualista hecha política se constituye en el alma del fascismo, generando un estado totalitario anterior a la Nación y a los derechos humanos, y consagrando la mística de la acción por la acción, que es como decir, el absoluto reinado de la sola fuerza.

Precedentemente calificamos al fascismo como un movimiento revolucionario. ¿Por qué razón? La cuestión se aclara cuando precisamos el concepto que tenemos en mente: revolución. La noción de revolución implica no sólo la idea del rechazo absoluto de la sociedad existente sino el mito de un estado final, de un estado perfecto dentro de la historia. La idea de revolución, en términos marxistas, equivale a la renuncia de la búsqueda metafísica; es decir, el revolucionario rechaza in totum la existencia de una racionalidad inmanente a lo real, al tiempo del primado de la contemplación (teoría) de dicho orden.

Esta negación primera del orden del ser le permite a la revolución generar un tipo antropológico esencialmente activo, apto para la instauración de una metahumanidad, caracterizada por la recuperación de aquellos poderes que el hombre había perdido al proyectarlos en Dios. Refiere Del Noce: "Si se quiere usar el lenguaje religioso podemos hablar, en referencia a la teoría de la Redención, de una autoliberación de la humanidad a través de la historia, o mejor, de una liberación operada por la historia, ya que en la segunda fase de Marx, aquella que comienza con las tesis sobre Feuerbach, desaparece la misma noción de naturaleza o de esencia del hombre $y$, por lo tanto, la humanidad antes que redimirse, es redimida por la historia, sin que por eso pueda hablarse de fatalismo" (Del Noce, 1992: 5-6).

En este sentido, De Felice no duda en calificar al fascismo de revolucionario en virtud de la movilidad que imprime a las masas y de la creación de un nuevo tipo de hombre (De Felice, 2008: 40). Y siguiendo a Del Noce en su análisis transpolítico del fascismo, sostenemos, en función de todo lo referido precedentemente, que la raíz primera del fascismo debe buscarse en la obra juvenil de Giovanni Gentile ${ }^{2}$ titulada La filosofia di Marx (Augusto Del Noce, 1990, 283). Esta obra debe ser situada dentro del contexto de revisionismo del marxismo que tuvo lugar en Europa hacia fines del siglo XIX. El término "revisionismo" fue usado por vez primera por Karl Kautsky (18541939) el cual, en su carácter de teórico marxista, desacreditó la posición Eduard Bernstein (1850-1932) calificándola de "revisionista". Bernstein hablaba de un socialismo de tinte democrático.

${ }^{2}$ Giovanni Gentile (1875-1944) ha sido uno de los más destacados filósofos italianos del siglo XX y, como dice Michele Federico Sciacca, “... el pensador en torno al cual, desde los prístinos años del 900 hasta cerca de 1930, ha gravitado casi toda la filosofía italiana y cuya influencia, aun desde el punto de vista crítico, todavía hoy está lejos de haberse extinguido" (Filosofía italiana del 900. Bs. As., Asociación Dante Alighieri, 1958, p. 87). 


\subsection{Tesis troncales de la filosofía peronista}

Juan Domingo Perón se dirige a los participantes del Congreso de 1949, celebrado en Mendoza, en estos términos: "He querido ofrecer a los señores que nos honran con su visita, una idea sintética de base filosófica, sobre lo que representa sociológicamente nuestra tercera posición" (Perón, 1949: tomo I, 131). Este texto es de fundamental importancia puesto que el propio Perón reconoce que en el mismo se encuentra plasmada la ideología del justicialismo. Afirma Perón que el "Justicialismo fijó su ideología en el Primer Congreso de Filosofía de Mendoza, que acaba de editarse nuevamente con el título de 'Una Comunidad Organizada' y que da el fundamento filosófico a la 'Doctrina Peronista (...)" (Perón, 1973: 153).

Considerando lo dicho precedentemente, nuestro estudio de la esencia filosófica del peronismo se centrará, fundamentalmente, en el análisis del texto referido, sin dejar de recurrir a otros que consideramos de relevancia en lo que respecta a la finalidad que perseguimos en este trabajo.

Más allá de las disputas acerca de quién ha sido el verdadero autor, lo cierto es que Perón jamás desautorizó el texto; es más, lo consideró como el manifiesto de la ideología de su autoría: el justicialismo.

El texto en cuestión no es de fácil lectura: la misma es tediosa, no resulta para nada amena. Se tiene la impresión de estar frente a una yuxtaposición de temas, sin orden ni concierto, que atenta contra la naturaleza unitaria de la inteligencia humana cuyo acto por excelencia es la síntesis. Pero si el lector es capaz de sortear esta seria dificultad y se esfuerza por comprender algunos principios unificadores del discurso, su esfuerzo tendrá su recompensa. Poniendo de manifiesto dichos principios, se estará en condiciones de re-componer todo el texto el cual adquiere una clara unidad inteligible. A partir de estos principios, estaremos en condiciones de configurar la doctrina que constituye la esencia del peronismo.

\subsubsection{Fatalismo histórico}

Señalamos anteriormente que, para Gentile, sólo el espíritu, en tanto movimiento inagotable, es la única realidad que tiene prioridad absoluta sobre el todo. Perón piensa en los mismos términos. La historia, para Perón, no está movida por las fuerzas materiales y las pasiones de los hombres, al modo marxista, sino por un espíritu que avanza de modo ineluctable (Perón, 1999: tomo IX, vol. 2, 544).

La historia, para Perón, sigue una ley necesaria: la de la evolución. Todo el escrito está configurado a partir de la categoría de "evolución" y no de revolución. La denominada, por Perón, ideología justicialista asume, por medio del empleo de esta categoría, una filosofía de la historia que concibe a esta última como el teatro de un avance progresivo e ineluctable. Para Perón, esta evolución, esta progresiva marcha de la humanidad hacia formas cada vez más perfeccionadas, se presenta como una instancia necesaria. "La humanidad tenía que evolucionar forzosamente hacia nuevas convenciones vitales y lo ha hecho" (Perón, 1949, 150).

Anteriormente, en el artículo publicado el 18 de junio de 1948 titulado "La libertad será la obligación de hacer lo que convenga a la colectividad", Perón sostiene: "Es un hecho cierto que no se puede detener la marcha de la humanidad hacia donde ella 
se encamine, y que cuando se ha infiltrado la tendencia a una idea, hay que aceptar el hecho y sacar del mismo el mejor provecho posible" (Perón, 1999: tomo X, vol. 2, 697). Por otra parte, en La Hora de los Pueblos, en el capítulo VI, punto 2, titulado "La Evolución", sostiene que no tiene sentido oponerse al progreso ya que, con oposición o sin ella, ha de triunfar insoslayablemente (Perón, 1973: 133) ${ }^{3}$. En esta obra sostiene, repetidas veces, su teoría del fatalismo evolutivo histórico (Perón, 1973: $12,19,21,84)$.

Lo dicho precedentemente no excluye la acción del hombre en la historia, antes bien la exige. La historia misma, nos dice Perón, da cuenta de eso (Perón, 1973: 21). Pero, nos aclara, la revolución debe ordenarse a la evolución. Afirma de modo explícito en uno de sus discursos: "Revolución, en su verdadera acepción, son los cambios estructurales necesarios que se practican para ponerse de acuerdo con la evolución de la humanidad, que es la que rige todos los cambios que han de realizarse" (Perón, 1974: 84). Y añade: "El hombre cree a menudo que él es el que produce la evolución. En esto, como en muchas otras cosas, el hombre es un poco 'angelito'. Porque es la evolución la que él tiene que aceptar y a la cual debe adaptarse. En consecuencia, la revolución por los cambios del sistema periférico, que es lo único que el hombre puede hacer, es para ponerse de acuerdo con esa evolución que él no domina, que es obra de la naturaleza y del fatalismo histórico. Él es solamente un agente que crea un sistema para servir a esa evolución y colocarse dentro de ella" (Perón: 1974: 88) ${ }^{4}$.

La revolución, entonces, es un verdadero acto de justicia que el revolucionario realiza respecto de la lógica interna que gobierna la historia por cuanto le otorga lo que ella exige en un determinado momento de la evolución universal. El revolucionario es el hombre que, mediante su acto, acelera los cambios ya que, de no hacerlo, se realizarán igualmente, debido a la fatalista lógica evolutiva de la historia. En la Hora de los Pueblos afirma: "No somos partidarios de una revolución cruenta ni violenta, como no compartimos la idea de una reforma 'por cambio' sino 'por evolución', porque no se pueden romper las instituciones sin provocar desequilibrios negativos y porque el camino de las reformas incruentas es lo racional cuando se trata de países civilizados" (Perón, 1973: 170). Pareciera que la posición de Perón es heredera de la concepción hegeliana de la libertad entendida como necesidad comprendida. Es decir, no concebida ya como poder de hacer o de no hacer, sino como acción razonable hecha posible por la conexión interna de momentos comprendidos en su sentido (Tosel Dictionnaire critique du marxisme), 1982: 511$)^{5}$.

\footnotetext{
${ }^{3}$ Lo destacado nos pertenece. A nadie escapa que ha sido Hegel quien ha pensado a la historia como historia del espíritu, y este espíritu jamás retorna a una figura anterior, sino que siempre resurge transfigurado y, de alguna manera, más elevado (cfr. Karl Löwith. Historia del mundo y salvación. Los presupuestos teológicos de la filosofía de la historia. trad. Bs. As., Katz, 2007, $1^{\text {a }}$ edición, p. 13).

${ }^{4}$ Ver, además, "Ante la convocatoria en el Teatro Colón". En Obras Completas. Op. cit., Tomo IX, vol. 2. Bs. As., Editorial Docencia, 1998, p. 357.

${ }^{5}$ Cfr. A. Tosel. "Liberté/Nécessité". En Dictionnaire critique du marxisme. Paris, P.U.F., 1982,

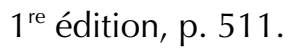




\subsubsection{El Estado ético}

Perón afirma que una de las evoluciones necesarias de la humanidad consistió en el pasaje del yo al nosotros (c). El mismo Perón, fiel a su concepción filosófica -la cual hemos comentado-, se autodefine como colectivista. Sostiene, sin ambages, "Nosotros somos colectivistas" (Perón, 1949: 173). Y afirma: "Al principio hegeliano de realización del yo en el nosotros, apuntamos la necesidad de que ese "nosotros" se realice y perfeccione por el yo" (Perón, 1949: 174. Sin embargo, el yo-creemossólo puede alcanzar su plenitud en el nosotros. En efecto, no hay individuo libre previamente a la constitución del Estado. Ese yo abstracto, sometido a sus instintos y pasiones no es libre; sólo alcanza la libertad cuando se adhiere a lo universal; sólo abrazando lo universal alcanza continuidad e identidad. Esto sucede solamente en la sociedad y en su voluntad política que es el Estado. Por eso nos parece que, pese a los esfuerzos dialécticos de Perón por mantener una armonía entre el Estado y la persona humana (sin sacrificar a ninguno de los dos términos (Perón, 1949: 159, 173 y 174), no logra su cometido en virtud de su posición de fondo. La persona humana termina siendo pensada a partir y en función del todo.

No podía ser de otra manera dada la asunción, por parte de Perón, de una filosofía del devenir. Escuchémoslo a él mismo: "La humanidad necesita fe en sus destinos y acción, y posee la clarividencia suficiente para entrever que el tránsito del yo al nosotros, no se opera meteóricamente como un exterminio de las individualidades, sino como una reafirmación de éstas en su función colectiva" (Perón, 1949: 150). Y continúa: "Si hay algo que ilumine nuestros pensamientos que haga perseverar en nuestra alma la alegría de vivir y de actuar, es nuestra fe en los valores individuales como base de redención y, al mismo tiempo, nuestra confianza de que no está lejano el día en que sea una persuasión vital el principio filosófico de que la plena realización del 'yo', el cumplimiento de sus fines más sustantivos, se halla en el bien general' (Perón, 1949: 160-161) ${ }^{6}$.

Es dado observar, en este punto, la convergencia entre las afirmaciones de Perón y las del creador del actualismo, Giovanni Gentile. Para Gentile, representarse a un hombre como anterior y exterior a la sociedad, condición, ésta, en que florecería la libertad, es una forma absolutamente abstracta (Gentile, La Riforma..., 2003: 27). El deseo inmediato del individuo no equivale a libertad: sólo es libre aquella actividad del Estado por cuanto el espíritu es actividad universal que une a los hombres y no los divide (Gentile, La Riforma..., 2003: 23). Expresa Gentile: "Mi voluntad, repito... es voluntad universal. Y una forma de la universalidad es la comunidad política, en la cual los individuos singulares se asocian y unifican en una superior individualidad históricamente distinta de otras afines" (Gentile, Sistemi di Logica come..., 2003: 317). Y prosigue: "... quien no está pronto a sacrificar siempre todo de sí y, por eso, todo su mundo inmediato, no está llamado a vivir la vida del espíritu... Se cierra en su propio egoísmo, y no ama. No ama la verdad, objeto en el cual brilla todo objeto determinado de nuestro amor; objeto que, como determinación de la verdad, no pide,

${ }^{6}$ Resulta curiosa esta afirmación a la luz de la declamada -por el mismo Perón- visión cristiana del justicialismo. Entendemos que, desde un punto de vista cristiano, el cumplimiento de los fines más sustantivos del hombre sólo se alcanza en Dios. 
al igual que ella, sacrificio y olvido de nosotros mismos, para la conquista de un yo superior".

Mi yo se encuentra como desdoblado: por un lado, existe un yo egoísta que se ocupa sólo de su propio bien y vive encerrado dentro de sí sin ser capaz de alcanzar una naturaleza superior, esto es, un yo de peso universal. De allí que al verdadero yo se lo pueda concebir como algo que es más que el individuo, como un todo social. Señala Berlin: "Al igual que en el caso del yo "positivamente" libre, esta entidad puede ser hinchada hasta convertirla en alguna entidad super-personal -un Estado, una clase, una nación o la marcha misma de la historia-, considerada como sujeto de atributos más "verdaderos" que el yo empírico" (1988: 204).

Ahora bien, el Estado, a través de la plasmación del "nosotros", permite al hombre la realización plena de la libertad. De allí que Perón agregue al sustantivo Estado el adjetivo "ético". Perón, cuando se refiere al Estado, lo designa, al igual que Gentile, como "Estado ético" (Perón, 1949: 172). Cada hombre se desarrolla como hombre a través de contactos interpersonales: "El hombre no es una personalidad libre hasta que aprende a respetar al prójimo" (Perón, 1949: 152). Expresa Perón: “... sólo en el dilatado marco de la convivencia puede producirse la personalidad libre, y no en el aislamiento..." (Perón, 1949: 152). El hombre no es libre sino en el seno del Estado. ¿Qué es el Estado? Es, como lo refiere la doctrina fascista, la "Multitud unificada bajo una idea... voluntad de existencia y de potencia: conciencia de sí, personalidad" (Perón, 1949: 152).

El estado es un sujeto o voluntad universal en el cual la voluntad de los individuos se unifican, deponiendo su individualidad. Esta concepción, nos dirán tanto Gentile como Perón, dista tanto del liberalismo como del socialismo ya que no anula ni la parte ni el todo. Nosotros advertimos, sin embargo, que en la doctrina peronista es el movimiento quien convierte al Estado en sujeto o voluntad universal, y configura a un pueblo otorgándole un mismo pensar, un mismo querer y un mismo sentir. Pareciera que Perón reconociese al yo cierta realidad independiente del nosotros cuando afirma que: "Al principio hegeliano del yo en el nosotros, apuntamos la necesidad de que ese 'nosotros' se realice y perfeccione por el yo" (Perón, 1949: 160-161); sin embargo, está expresando lo contrario. En efecto, Perón está sosteniendo que el nosotros no se configura como tal sino por un yo que, haciéndose pleno, deja de serlo, para adquirir un mismo pensar, un mismo querer, un mismo sentir. El yo es sólo un momento irrelevante en un proceso ordenado a la consolidación de un nosotros.

Perón piensa en la existencia de un hombre colectivo, que debe constituirse como tal a partir de la asunción, in interiore, de la visión universal que radica en la voluntad del que conduce la Nación. Lo universal se erige en lo bueno; lo individual, en lo malo.

En el sistema de Hegel no hay lugar para lo individual, lo cual está destinado a perecer para dar lugar a lo universal. Señala al respecto A. Kojève: "Aquello que transforma la teología en antropología es la introducción en la misma de la idea de la muerte. Y solo aceptando integralmente esta idea, o sea, suprimiendo las ideas de sobrevivencia y de resurrección, se llega a la antropología verdadera, o hegeliana" (Koyève, 1973: 201). Esta concepción filosófica estará en la base de los sistemas 
totalitarios del siglo XX. La univocidad del ser conduce, en política, a la negación de lo diverso. Y la unicidad política está representada por el Estado. De allí, que el fascismo afirme: "Todo dentro del Estado y nada fuera del Estado".

Para Perón, quien sigue en esto a Gentile, la individualidad no se justifica desde sí misma. Sólo un acto puede redimirla: precisamente, el acto a través del cual esa individualidad se hace universal haciendo suya la perspectiva del todo, la perspectiva universal.

\subsubsection{Las dos Argentinas o la guerra intestina}

Ya expresamos que la historia, para Perón, sigue una ley necesaria: la de la evolución. Para él, este fatalismo evolutivo consiste en una progresiva marcha de la humanidad hacia formas cada vez más perfeccionadas (Perón, 1949: 150). Al hombre sólo le quedan dos caminos: o acompañar esta marcha evolutiva, o no hacerlo. El éxito del peronismo ha radicado en seguir esa evolución, y su líder ha sido quien ha sabido leerla. De este modo, su voluntad se ha convertido en buena toda vez que ha seguido la voluntad universal inmanente a la historia. Esta buena voluntad, en tanto universal, se enfrentará con aquellas otras voluntades que, en lugar de preferirla, optarán por su propio querer. Estas voluntades antagónicas son las que dan lugar a dos formas de ciudadanos: los hombres nacionales que pliegan su voluntad a la voluntad universal, y la de los cipayos, vende-patria, anti-nacionales, que prefieren su propio querer.

La guerra, entonces, es interna al mismo país y se mantiene mientras las voluntades réprobas no adhieran a la voluntad del líder, que es como decir, a la voluntad del logos universal con la cual el líder está identificado. La patria habrá alcanzado su salvación cuando en cada ciudadano exista un mismo pensar, un mismo querer y un mismo sentir. Cuando esto suceda, sólo quedará en pie una sola Argentina y se habrá sepultado, de modo definitivo, la otra Argentina de los intereses egoístas.

Son estas voluntades antagónicas las que dan lugar a dos formas de ciudadanos: los hombres nacionales que equiparan su voluntad con la del líder (esta última, identificada, a su vez, con la evolución fatalista de la historia), y la de los cipayos, vende-patria, anti-nacionales. La guerra, entonces, es interna al país, por cuanto es en el seno del mismo que se yergue una fuerza que quiere oponerse al pensar y al querer único del Estado manifestado en el pensar y en el querer del conductor.

Perón, reeditando al fascismo en su versión de las dos Italias, estableció la existencia de las dos Argentinas. Esta afirmación es el resultado directo, a nuestro juicio, de su visión filosófica de la historia.

En el primer capítulo de la primera parte de la obra de Gentile titulada Le origini dell'ideologia fascista, titulada "Le due anime del popolo italiano prima della guerra", el filósofo italiano describe al enemigo interno. Este enemigo no es un enemigo de clase, sino el italiano personificado en Mazzini, hombre experto en todos los vicios y valores de todo el mecanismo político y administrativo, simplificador de todas las grandes cuestiones, incapaz de todo entusiasmo y de elevadas afirmaciones, hombre práctico, egoísta, cuya concepción materialista de la vida, al igual que la del socialismo, niega la existencia de una realidad superior a la vida material que tiene su medida en el mero individuo (1934: 24-25). El peronismo, al igual que el fascismo 
italiano, no es clasista. Cualquier argentino de "buena voluntad" ("buena" cuando se identifica con la voluntad universal del líder que gobierna los destinos de la Nación), pertenece al movimiento nacional y popular. Refiere Perón: "Me interesa advertir que nosotros no teníamos un partido. Hemos sido siempre un movimiento nacional que integraba a numerosos partidos y sectores independientes, entre ellos el laborista, que reunía toda la clase obrera. Pero no constituimos un movimiento clasista sólo de obreros, como algunos han creído. En nuestro movimiento había muchos profesionales y aun de las clases altas había gentes con nosotros" (Perón, 1981: 7677).

El peronismo, al igual que el fascismo, no es la revolución dentro del estado, sino, como bien señala Del Noce, el estado contra los residuos y los detractores que obstaculizan su organización, su unidad plena (Del Noce, 1990: 304). La vocación totalitaria está, toda ella, presente en una voluntad que es la única legítima por cuanto sólo ella puede esgrimir el título de universal. Si bien esa voluntad está presente en un individuo, sin embargo este último ha dejado de serlo cuando se ha hecho uno con la voluntad universal de la fatal evolución.

Consideramos que en la afirmación de la identificación de la voluntad del líder con el sentido de la historia se funda la raíz última de los totalitarismos en sus diversos grados. La diversidad de grados es consecuencia, a nuestro juicio, de la existencia de una fuerza externa a la referida voluntad que impide que ésta se convierta en el todo de la Nación. De allí que todo totalitarismo, además de su voluntad intrínseca destinada a hacerse todo, requiera de la defección de las voluntades de todos los ciudadanos.

Convertir la voluntad de un hombre en la voluntad universal es la raíz más profunda de los totalitarismos y de la violencia política. Por violencia, señala Del Noce, debe entenderse "la reducción del individuo humano a 'ser para otro'..." (Del Noce, 2001, 233). Y añade, "... cuando este otro no es algo que "es" (tiene una existencia de hecho) sino que "debe ser", es decir, un valor (c), se tiene la violencia política..." (Del Noce, 2001: 233). Desde esta perspectiva, la persona humana no tiene una dignidad que le sea intrínseca, fundada en su propio ser, sino que su dignidad es proporcional a los ideales que ha asumido. Su dignidad depende de la asunción de aquellos ideales que el movimiento vaya determinando en cada circunstancia histórica. La enajenación de la voluntad propia por parte del nosotros, del yo colectivo, es total.

\subsubsection{La esencial labilidad de la doctrina}

Advertimos, en este punto, que Perón admite un telos histórico que da sentido al conjunto de hechos o acontecimientos. Pareciera que el telos estuviese constituido por el progreso hacia la adquisición plena de la libertad del hombre (forma más alta del desarrollo de la vida). Las ideas de los hombres, en este sentido, no son configuradoras de la historia sino que constituyen un mero reflejo de la marcha de la misma en determinado momento histórico -reflejo, éste, que equivale a una sintonía con el logos o espíritu inmanente que gobierna la historia-. 
Pero ese logos, esa fuerza que, invisiblemente, gobierna los hechos históricos, no es una realidad estática, inmutable, sino esencialmente dinámica. Su ser es un continuo hacerse, un farsi eterno; y este hacerse permanente se concreta en la historicidad. El hombre, el singular, puede descubrir la trama evolutiva de la historia y, de esta manera, hacerse partícipe de la misma. Y como la misma es devenir, todas sus categorías de análisis, si es que quiere permanecer dentro de la historia, no pueden ser sino esencialmente fluidas. De allí entonces que, tanto la vida individual como política, no puedan regirse por principios permanentes sino por la constante huida de todo principio permanente.

Lo afirmado hasta el momento nos permite determinar el valor que Perón otorgaba a la doctrina por él formulada. La doctrina peronista tiene un núcleo invariable: lo invariable de la realidad es lo variable. De allí que todo otro principio, reflejo de un determinado momento histórico, deba ser inmediatamente abandonado cuando ha dejado de tener vigencia. Podríamos decir que la doctrina justicialista está configurada por un conjunto de ideas que son el reflejo del momento histórico en que Perón las configuró, excepto el principio por excelencia: la variabilidad esencial de todo principio.

Este principio no es un significante vacío sino completamente lleno, tan colmado que configura la política y la vida individual de los hombres. Todas las demás ideas poseen un contenido hic et nunc, esencialmente variable, y se constituyen en herramientas aptas para posicionarse, los más ventajosamente posible, en el devenir histórico. En la doctrina peronista nada hay de definitivo: todo se re-significa in aeternum.

Fiel al Devenir, como principio constitutivo de lo real, Perón no sólo declara provisoria a la doctrina peronista sino a toda doctrina, incluidas las religiosas. Expresa Perón: "Una doctrina no puede ser sino circunstancial, las doctrinas políticas no son eternas, quizás las religiosas puedan ser eternas a pesar de los inconvenientes que la eternidad trae a todas las doctrinas" (Perón, 1999: tomo XI, vol. 2, 556). Al respecto, nos permitimos transcribir una cita perteneciente a Benito Mussolini para que el lector pueda advertir la plena convergencia entre el pensamiento del Duce y el del general argentino. Mussolini expresaba en el año 1921: "Nosotros no creemos en los programas dogmáticos... Nosotros nos permitimos el lujo de ser aristócratas y demócratas, conservadores y progresistas, reaccionarios y revolucionarios, legalistas y no legalistas, según las circunstancias de tiempo, de lugar, de ambiente" (Mussolini, 1934, 153).

Ahora bien, ¿quién o quiénes, dentro del movimiento peronista, determinarán el sentido de la historia?

Este interrogante tiene, dentro del peronismo, una respuesta unívoca: el líder del movimiento. Su condición de líder se ha determinado, precisamente, por haber sido el que ha descifrado el sentido del tiempo y el que ha tenido la voluntad para hacer que los hombres siguieran dicho sentido. El líder es el héroe que "...se despersonaliza y se convierte en el espíritu de su pueblo..." (Gentile, 1934: 77). La demostración de su liderazgo está dada por su éxito, por haber hecho de su voluntad la voluntad de la nación. Claro está que esta voluntad no es la voluntad individual del líder sino la 
voluntad del logos universal a la cual él ha conformado su voluntad individual. Perón es el estratega del movimiento peronista porque sólo su espíritu ha sido capaz de coincidir con la finalidad hacia la que se dirigía la historia en el tiempo que le tocó vivir.

El peronismo es, en realidad, una verdadera religión secular, que hace de cada ciudadano un hombre religado a la voluntad del líder, voluntad, ésta, identificada con el sentido histórico de un tiempo determinado de la vida de la Nación. Sus militantes son poseedores de una mística, de una actividad espiritual que es manifestación de la profunda unión con la voluntad del líder y con la voluntad de la Nación.

\subsubsection{El activismo}

El peronismo ha plasmado, en Argentina, una praxis política dominada in totum por el activismo. Esta filosofía es la manifestación de aquello que, según Augusto Del Noce, Eric Voegelin calificara como "espíritu de modernidad" (Del Noce, 1968: 9), entendiendo por espíritu de modernidad aquella posición que sostiene que lo propio del hombre es su capacidad de ir más allá de sí mismo. Esta afirmación equivaldría a sostener que la transgresión, el romper con todo lo dado, el rechazo de todo límite, comenzando por la misma naturaleza, es la esencia propia del hombre. De este modo todo el ser del hombre se identifica con la acción. En efecto, es esta última quien debe prolongarse, in infinitum, desde su negación primera. No puede detenerse ya que ello equivaldría a ser presa de algún límite. El mal, dentro de esta lógica, se identifica con el límite. Límite equivale a represión o ahogamiento de ese ir siempre más allá de sí mismo. La vida del espíritu es, propiamente, una acción sin fin. De allí, entonces, que para el espíritu de modernidad deba abandonarse definitivamente la teoría, esto es, aquel acto de ver, de leer dentro de las cosas para aprehender aquello que ellas son. Sostener que el primer acto del hombre es un "ver" que tiene por objeto el ser de las cosas y no un querer trascenderse, equivale a sostener que el hombre es teórico y que está movido por la verdad, verdad, ésta, que se convierte en la guía de su acción.

Escapar de este espíritu teorético exige, tal como le enseñaba Donato Jaja a su discípulo Givanni Gentile, el rechazo absoluto de la idea de intuición. Hablar en términos de intuición supone admitir la existencia de una realidad ordenada que existe antes del querer y amerita ser conocida. La intuición concibe al conocimiento en términos de visión y no, como el revolucionario pretende, en términos de construcción. Leo Strauss describe, en el ámbito de la política, aquello que sucede cuando se abandona el concepto de teoría como el ver aquello que las cosas son. Refiere Strauss: "La teoría política se convierte en inteligencia de aquello que la práctica ha producido, la inteligencia de la realidad efectual, dejando de ser la búsqueda de aquello que debería ser... Aparece ahora un tipo nuevo de teoría o de metafísica, teniendo por tema supremo la actividad humana y aquello que ella genera, en lugar del Todo, que no es, de modo alguno, un objeto de la actividad humana. Dentro del Todo y dentro de la metafísica que se apoya sobre él, la actividad humana ocupa un puesto elevado, pero secundario. Cuando la metafísica viene, como sucede ahora, a considerar la actividad humana y aquello que ella genera como el fin al cual todo otro ser o proceso está enderezado, la metafísica se convierte en filosofía de la historia" (Strauss, 1990, 344). 
Esta lógica activista se hace una sola con la idea de revolución, la cual, en el más riguroso de sus significados, consiste en la sustitución de la búsqueda metafísica, esto es, la búsqueda de la racionalidad existente en las entrañas de lo real y el consecuente primado de teoría de dicho orden por el cual la acción humana debe regirse, por la afirmación de un poder humano capaz de ir siempre más allá de todo lo dado, de todo límite. De allí, entonces, la existencia de un mundo cuya clave de bóveda es el poder y no la verdad. La verdad no puede tener lugar alguno dentro de una lógica de la pura acción que no puede reconocer guía alguna.

El activismo al que nos venimos refiriendo, nos dice Del Noce, es aquella tensión del espíritu hacia una acción que no es querida en cuanto dirigida a un orden, sino que es querida por sí misma. En este sentido, señala Del Noce, todo valor deviene puro instrumento ordenado a la promoción de la acción. Nada ni nadie puede interponerse en el camino de la acción. Cuando decimos nadie estamos refiriéndonos a la mismísima persona humana. Si esta última, al igual que cualquier valor, deviene obstáculo de la acción, deberá ser aplastada (Del Noce, 1992: 352-353). El activista no puede considerar, al modo de Kant, a la persona humana como fin de sus acciones sino sólo a su misma acción.

El activismo conduce, de modo inexorable, al nihilismo de los valores. De allí que en una sociedad configurada en torno al mismo, pierda sentido la misma noción de consenso ya que no existe valor alguno sobre el cual poder consensuar. En efecto, resulta imposible, en la comunidad política, alcanzar algún entendimiento en torno a valores a poner en práctica. El activismo conduce, de modo inexorable, a un nihilismo disgregador de toda vida individual y comunitaria.

\section{BIBLIOGRAFÍA}

Berlin, I. (1988). Cuatro ensayos sobre la libertad. Madrid: Alianza Editorial.

Conferencia del Excmo. Señor Presidente de la Nación, General Juan D. Perón. En Actas del Primer Congreso Nacional de Filosofía, Mendoza, marzo 30 - abril 9, 1949, tomo I.

De Felice, R. (2008). Intervista sul fascismo. Roma-Bari: Laterza, $5^{\text {a }}$ edizione.

De Felice, R. (1976). Le interpretazioni del fascismo. Roma-Bari: Laterza.

Del Barco, R. (1983) El régimen peronista 1946-1955. Bs. As.: Editorial de Belgrano.

Del Noce, A. (2001) "Cristianesimo e política". En Scritti politici. 1930-1950. Soveria Mannelli: Rubbetino.

Del Noce, A. (1990) Giovanni Gentile. Per una interpretazione filosofica della storia contemporanea. Bologna: Il Mulino.

Del Noce, A. (1992) // suicidio della Rivoluzione. Milano: Rusconi, $2^{\mathrm{a}}$ edizione.

Enciclopedia italiana di Scienze, Lettere ed Arti, 1932. Voce Fascismo, vol XIV.

Fayt, C. S. (2007) La Naturaleza del Peronismo. Bs. As.: Errepar. 
Genta, J. B. (s/f). El nacionalismo argentino. Bs. As.: Editorial Cultura Argentina.

Gentile, G. (2003) La filosofia di Marx. Firenze: Le Lettere.

Gentile, G. (2003) La Riforma dell'educazione. Discorsi ai maestri di Trieste. Firenze: Le Lettere, quinta edizione riveduta.

Gentile, G. (1934) Origini e dottrina del fascismo. Roma: Istituto nazionale fascista di cultura, $3^{\text {a }}$ ediz.

Gentile, G. (2003) Sistemi di Logica come teoria del conoscere. Firenze: Le Lettere, vol. II, $5^{\text {a }}$ ediz. riveduta.

Germani, G. (1968) Política y sociedad en una época de transición. Bs. As.: 1968.

Gramsci, A. (2001) Quaderni del carcere. Volume secondo. Edizione critica dell'Istituto Gramsci. Quaderno 10 (XXXIII) 1932-1935. Torino: Einaudi, $2^{\text {a }}$ edizione.

Kojève, A. (1973) La dialettica e l'idea della morte en Hegel. Torino: Einaudi, seconda edizione.

Lasa, Carlos Daniel. ¿Qué es el peronismo? Una mirada transpolítica. Salta, EUCASA, 2018.

Meinvielle, Julio. (1974) Concepción católica de la política. Bs. As.: Dictio.

Mussolini, B. (1934) Scritti e discorsi. Milano: Hoelpi, vol. II.

Perón, J. D. (1973) Juan Perón. La Hora de los Pueblos. Bs. As.: Ediciones Presente.

Perón, J. D. (1999). Obras Completas. Bs. As.: Editorial Docencia, 40 vols.

Samyn Duco, E. J. (1978) Universalidad del nacionalismo. (Ensayo sobre sus posibilidades filosóficas). Bs. As.

Sciacca, M. F. (1958) Filosofía italiana del 900. Bs. As.: Asociación Dante Alighieri.

Tosel, André (1982). "Liberté/Nécessité". En Dictionnaire critique du marxisme. Paris: P.U.F., $1^{\text {re }}$ édition.

Perón, J.D. (1981). Yo, Juan Domingo Perón. Relato autobiográfico. Barcelona: Editorial Planeta, $2^{a}$ edición. 